Est Ag 42 (2007) 509-536

\title{
El seguimiento de Cristo en la formación agustiniana: oración, comunidad, misión
}

\section{Introducción}

La Formación Inicial, después del Vaticano II, no ha mejorado excesivamente, aunque hayan mejorado muchas cosas en el proceso formativo ${ }^{1}$. La dolorida declaración de Clodovis Boff, ante ciertas situaciones de la Formación actual, demuestra que esto es así2. Por nuestra parte, hemos constatado repetidamente que el número de abandonos de la vida religiosa, entre la primera profesión y los 10 primeros años, tras la profesión solemne, puede acercarse a la mitad. El que las cifras de las rupturas matrimoniales también sean muy altas no es ningún consuelo. Todo esto debe hacernos pensar...

Hoy la formación, en el fondo, no influye demasiado en muchas de las personas que la recibe, y conduce fácilmente al desarrollo del 'efecto túnel' del Noviciado, y a 'la existencia como plenitud de la excelencia' en el Profesorio. Así, la formación lleva, a veces, más a facilitar la creación del 'nido' o acomodación a la vida religiosa, tal como la describe Rulla y su equipo, que a formar verdaderos seguidores de Jesús.

Es necesario e ineludible afrontar los problemas y carencias en formación humana, formación religiosa, comunitaria, apostólica y agustiniana. Esto mismo ha de hacerse en la formación permanente ${ }^{3}$. Una de esas carencias es, en nuestra opinión, privilegiar solamente un aspecto de la vida religiosa, de modo que se separa fácilmente la misión de la comuni-

${ }^{1}$ L.M. Rulla, F. ImOdA, J. RIdICK, Antropología de la vocación cristiana. II ${ }^{\circ}$. Madrid 1994.

2 C. Boff, Cuatro o cinco consideraciones que surgen de la indignación sobre la formación para la vida religiosa hoy. Boletín de OALA 77 (1998) 27-32.

3 A. MANENTI, Vivir en comunidad. Aspectos psicológicos. S. 1984, $2^{\text {a }}$. 
dad o de la oración y viceversa, lo que conduce a la desintegración de la vida religiosa con muy graves consecuencias 4 .

De ahí la necesidad de promover una formación íntegra, integral e integradora que anime el pluralismo y el diálogo intercultural, favorezca el aprecio personal y la formación humana, la confianza comunitaria y el trabajo en equipo, la responsabilidad y el compromiso con los problemas de la Iglesia y del mundo5. Pues: "La formación es un proceso vital a través del cual la persona se convierte al Verbo de Dios, desde lo más profundo de su ser y, al mismo tiempo, aprende el arte de buscar los signos de Dios en las realidades del mundo":VC 68.

\section{El seguimiento de Jesús en la interioridad, comunidad, misión}

1. El seguimiento de Jesús, tal como se presenta en el Evangelio, es la clave de la vida religiosa, su norma última y regla suprema, dice el Concilio Vaticano II $^{6}$. Actualmente hay un acuerdo general en que este seguimiento de Jesús consiste en vivir la experiencia de fe de Jesús, continuar la comunidad de Jesús y desarrollar la misión de Jesús.

Así se presenta en el documento del Sínodo sobre la Vida Religiosa, Vita Consecrata, Roma 1996, y así aparece también en muchos documentos de la Iglesia, sobre la vida religiosa, por ejemplo, en La vida fraterna en comunidad, Roma 1994. También esto es así en los documentos de la Orden Agustiniana, según trataremos de hacer ver.

1.1. El seguimiento de Jesús, en la exhortación apostólica sobre $L a$ Vida Consagrada, se articula en tres capítulos, a los que precede una Introducción sobre la historia y la situación actual de la vida religiosa, y una Conclusión, mirando al futuro, porque la vida religiosa no tiene solamente un pasado glorioso que añorar sino una gran historia que construir: VC 110 .

El capítulo $\mathrm{I}^{\mathrm{o}}$, bajo el título, Confessio Trinitatis presenta las fuentes cristológico-trinitarias, eclesiales y espirituales de la vida religiosa. En este apartado, la experiencia de la fe, la vida de oración y la aspiración a la san-

4 F. GALENDE, El profetismo de los votos. Curso de formadores Agustinos. Panamá $1998,4$.

5 D. Goleman, La práctica de la inteligencia emocional. B. 1999, 427, 384. En inglés: Bantam Books 1999, 373, 335.

6 Perfectae Caritatis 2. 
tidad son temas fundamentales. La inmersión en el misterio de Dios, su vivencia personal y comunitaria, que debe transfigurar la vida del individuo y del grupo, se ven como imprescindibles.

El cap. II $^{\circ}$, con el título, Signum fraternitatis, expone todo lo relativo a la vida de comunión trinitaria, eclesial y fraterna. El mandamiento nuevo, de Cristo, es como la realización suprema de la vida religiosa por la caridad. Se afirma que esta comunión fraterna es decisiva para la vida religiosa, activa y contemplativa, a imagen de la Trinidad. Así, la experiencia del amor cristiano, la caridad y la comunidad se presentan, en la vida religiosa, como un signo de esperanza para todos los creyentes y para todos los hombres de buena voluntad frente al individualismo y la insolidaridad egoísta.

Finalmente, el cap. III ${ }^{\circ}$ de La Vida consagrada, bajo el título, Servitium caritatis, nos presenta la Misión de la vida religiosa, en la Iglesia y en el mundo actual, como la difusión del amor de Cristo a todos los pueblos de la tierra por la nueva evangelización, la inculturación, el profetismo de la vida consagrada, en todos los campos de la misión, como pueden ser: la educación, la opción por los pobres y la promoción de la justicia, el diálogo con las culturas y con las diversas religiones de nuestro tiempo. Así nos encontramos con la esperanza y el futuro, el trabajo por el Reino, la misión y el apostolado.

El documento sobre La vida fraterna en comunidad, presenta una comunidad religiosa que integra las tres dimensiones fundamentales del seguimiento de Jesús, y la ve como una comunidad en comunión, con Dios y con los hombres, que así realiza la vocación fundamental del ser huma$\mathrm{no}^{7}$. Al hombre le ofrece la comunión Trinitaria cuando ora y celebra su fe (capítulo $\mathrm{I}^{\circ}$ ), una comunidad en comunión fraterna y eclesial, como don y tarea, bajo la acción del Espíritu Santo que es amor (cap. $\mathrm{II}^{\circ}$ ), y una comunidad empujada a la misión por el Espíritu que así la hace apostólica (cap. III $^{\circ}$ ).

1.2. El Documento de Dublín, del Capítulo General Intermedio de 1974, fue un momento profético, en la vida de la Orden Agustiniana, al sintetizar lo fundamental de su espiritualidad y hacer una meditación agustiniana sobre la experiencia del carisma agustiniano en el mundo de hoy. Su esquema, con casi 20 años de antelación, es idéntico al que presenta Vita Consecrata. El capítulo $\mathrm{I}^{\circ}$, titulado: La situación del Mundo y de la Iglesia, es como una Introducción, y da cuenta de la realidad de la so-

${ }^{7}$ La Vida Fraterna en Comunidad. Roma 1994, 9 
ciedad actual, en cuanto a la aceleración de la historia, socialización, secularización y personalización, así como los nuevos acentos de la experiencia de la Iglesia pueblo de Dios, Iglesia comunión y oyente de la Palabra al servicio del Reino, y Sacramento universal de salvación con sus preocupaciones o dificultades más importantes en el mundo actual.

El cap. II $^{\circ}$ se centra en la Espiritualidad agustiniana, en relación con nuestra misión en el mundo. Se cita el tema de la comunidad como fundamental, la amistad, las buenas relaciones humanas, y la vida de convivencia fraterna. Se presenta la búsqueda de Dios como una cuestión esencial en nuestro mundo. Se insiste en el amor integral, a Dios y a los hermanos, como "un punto destacado en los escritos de san Agustín". Se señala también, la tensión escatológica de la ciudad de Dios, y se contempla la autoridad como un servicio de personas libres bajo la gracia.

El cap. III $^{\circ}$ describe La vida comunitaria hoy, y se afirma, de acuerdo con nuestras Constituciones $\mathrm{n}^{\circ} 8$, que "el fundamento de la vida agustiniana es la vida común" plena, siguiendo el deseo de Cristo: que nos amenos y seamos todos uno. Cada comunidad, y todas juntas, son una pequeña Iglesia como la comunidad primera de Jerusalén, llamada por el Espíritu a la Misión. Se invita al gozo de la amistad, a la comunión y a compartir la vida, a la oración participada, al pluralismo en la unidad, y a construir y vivir la auténtica comunidad.

Se incita también a ser testimonio de pobreza y de comunidad de bienes, y se presenta la castidad como entrega incondicional a Dios y a la humanidad que sufre. Además, el $\mathrm{n}^{\circ} .64$ de este Documento dice así literalmente: "El Capítulo está convencido de que si nosotros Agustinos no conseguimos una renovación de la vida común, a la luz del Nuevo Testamento y del espíritu de san Agustín, el resto de nuestros problemas (crisis de vocaciones, crisis de identidad, problemas apostólicos, etc.) no se resolverán ni surgirá una nueva vitalidad en la Orden".

El cap. IV ${ }^{\circ}$ se dedica a la Misión bajo el título Nuestro apostolado. Se invita a la renovación, al compromiso con los pobres y la liberación humana, a nuevas iniciativas, a la preparación adecuada, y recuerda el sentido comunitario del apostolado agustiniano.

Finalmente, el cap. V afronta el desafío de la experimentación, de cara al futuro, bajo el impulso del Espíritu, de acuerdo con la naturaleza de la Orden, pero aceptando también el riesgo necesario para no quedar paralizados.

La Ratio Institutionis (1993) de la Orden Agustiniana, tras las huellas del documento de Dublín y de la vida de la Orden en el mundo actual, 
afirma lo siguiente: "Esta formación debería desarrollarse siempre desde la comunidad de vida, la comunidad de fe y de apostolado que constituyen la quintaesencia de la comunidad agustiniana": RI 85. Cuando se describen los elementos básicos de la Formación agustiniana se habla de:

$1^{\circ}$. Compartir la vida en Comunidad: RI 16-44.

$2^{\circ}$. Compartir la búsqueda de Dios en comunidad (RI 45-55) y

$3^{\circ}$. Compartir el apostolado en comunidad: RI 56-67. Al describir la formación por etapas también aparecen claramente estos tres centros de interés: interioridad, comunidad y misión. Es de notar, que en todo el documento se ha dado prioridad a la comunidad como elemento integrador. El programa ha reservado también un espacio adecuado a la formación humana y al contexto humano, social y cultural (RI 68-71).

En las Constituciones, se puede decir que, como es lógico, también se observa el mismo planteamiento. Así lo podemos ver, en los distintos apartados, al tratar:

$1^{\circ}$. de la consagración y la búsqueda de Dios $\left(\mathrm{n}^{\circ} 1-4,17-35\right)$.

$2^{\circ}$. de la vida de comunidad ( $\mathrm{n}^{\circ} \mathrm{s} 7-14$ y 112-123),

$3^{\circ}$. y de las actividades apostólicas ( $\mathrm{n}^{\circ} \mathrm{s} 39-41$ y 157-199).

Estas tres dimensiones se pueden unir e integrar de diversos modos, dando como resultado diversos modelos o formas de vida común según se insista más en el apostolado de la educación, o en la acción social, o en la actividad parroquial o misionera o ecuménica o en otras diversas acciones.

En Agustinos en la Iglesia para el mundo de hoy, podemos encontrar las mismas líneas fundamentales:

$1^{\circ}$. Volver sobre nuestro espíritu (Agustinos en la Iglesia, 2 - 6).

$2^{\circ}$. Evangelizar desde la comunidad (Agustinos en la Iglesia, 7-15).

$3^{\circ}$. Respuesta a los desafíos pastorales de la Iglesia (Agustinos en la Iglesia, 23-31).

La integración de los tres dimensiones en la identidad y el carisma agustiniano puede ser muy variada pero los tres elementos han de estar siempre activos. No se puede vivir nuestra espiritualidad a trozos, ni con polarizaciones de un aspecto $u$ otro de la vida religiosa, pues, como se ha dicho muy bien: "Las opciones realizadas por la Orden, en los treinta años del post-concilio, en torno a las características fundamentales de nuestra espiritualidad se han centrado, sobre todo, en la vida comunitaria, de la 
que dimana la búsqueda de Dios, particularmente por la vía de la interioridad y la disponibilidad para el servicio a la Iglesia"8.

\section{3. El verdadero san Agustín y su integración en la Formación ac- tual: Interioridad, Comunidad, Misión}

Cuando la Comisión Internacional, nombrada por el Consejo General de la Orden, redactaba el Plan de Formación Agustiniana (Ratio Institutionis) recibimos muchas sugerencias. Algunos pensaban que debíamos centrarnos en la Comunidad por ser el elemento nuclear en san Agustín. Otros advertían que no se debía olvidar que la Oración es el alma de nuestra vida religiosa: cuando la oración falla todo se hunde, y además san Agustín fue el maestro de la interioridad, y el teólogo de la Trinidad. Otros nos recordaban, con la misma vehemencia, que san Agustín fue sobre todo un Pastor, y que un programa que olvidase esta cuestión, edificaría en falso y sería un rotundo fracaso. Así pues deberíamos buscar el verdadero san Agustín, el Verus Augustinus.

1.3.1.- Para unos, el verdadero san Agustín sería el gran pastor al servicio de la Iglesia. Y de ahí el: contemplata aliis tradere ${ }^{9}$. Nuestro apostolado, el servicio a la Iglesia, nos definió siempre: en el comienzo, en la edad media y en el mundo actual: Const. 157-199. La comunidad no nace para encerrarse en sí misma sino para ser luz en el camino. La preocupación de san Agustín por el pueblo y especialmente por los más desamparados define hoy nuestro carisma y su misión de justicia ${ }^{10}$.

1.3.2.- Para otros, el verdadero san Agustín sería el hombre de la interioridad, el pensador más importante del mundo latino (H. Arendt), el primer hombre moderno (Harnack), el creador de la antropología y de la psicología del yo (J. L. Pinillos) y, sólo desde ahí, de la vida religiosa en seguimiento de Cristo ${ }^{11}$. No en vano el redactor de La Imitación de Cristo

8 Discurso de inauguración del Capitulo General Intermedio, Villanova (USA), en Agustinos en la Iglesia para el mundo de hoy, Roma 1998, 45. Cf. también T.J. van Bavel, Espiritualidad agustiniana para la Iglesia en el mundo moderno, en La familia Agustiniana ante el tercer milenio. Roma 1999, 44 y ss.

${ }^{9}$ F. van DeR MEer, San Agustín pastor de almas. Vida y obra de un Padre de la Iglesia. B. 1965.

${ }^{10}$ Los Agustinos hacia el 2000. Cap. General 1989, 2 y 3.

11 E. PrZYwara, El pensamiento de san Agustín. Trad. L. Cilleruelo. M. 1986. 
bebió en fuentes espirituales agustinianas. En efecto, para san Agustín, Cristo es nuestra origen, Cristo es nuestra forma y nuestra raíz: radix nostra Christus est: Contra litt. Petiliani 1, 7, 8. Por tanto, la configuración con Cristo: interioridad, conversión, oración, esperanza, aspiración a la santidad, "sed imitadores de Dios como hijos queridos" (Ef 5,1), definen nuestra espiritualidad, y eso es lo decisivo.

1.3.3. Según otros, el verdadero san Agustín se manifiesta por la amistad y la vida en comunidad. Agustín se hace monje a imitación de la primera comunidad de Jerusalén ${ }^{12}$. Lo recordaba el documento de Dublín, en el texto ya citado: La Orden está convencida que sin la renovación de la vida común, los demás problemas no tienen solución... Ciertamente, no debemos olvidar, que esa comunidad, además de comunidad de convivencia, es comunidad de oración y celebración y comunidad de trabajo y apostolado. De hecho, la comunidad agustiniana define y expresa toda nuestra vida religiosa y toda nuestra espiritualidad: "para nosotros agustinos se encuentra en el corazón de nuestra identidad y de nuestro carisma": RI 76.

Conviene, pues, pensar que quizá hay tres imágenes de Agustín y uno sólo verdadero:

1.3.4.- El verdadero san Agustín es a la vez: Pastor, Pensador, Amigo de sus amigos. Buscador de la verdad. El primer pensador de la latinidad. El santo amigo (Machado). El pastor entregado a su pueblo, sin el cual no quiere salvarse. Interioridad, comunidad y misión, resumen su proyecto. Son las tres dimensiones profundas que mueven la comunidad, reflejo de la Trinidad (RI 73): Dios es Misterio, Dios es Amor, Dios es Salvador. El Misterio nos llama a la Interioridad, el Amor a la Comunidad y el Dios Salvador a la misión en la Nueva Ciudad de Dios.

En cada comunidad, las tres dimensiones, de la vida religiosa, son fundamentales, pero en cada caso se viven de una forma concreta según la situación cultural y según las actividades apostólicas que el pueblo nos reclama. Un sano equilibrio, entre los diversos valores de la vida común, con la valentía profética de cada una, ayuda mucho a mejorar la vida religiosa y comunitaria.

12 Manrique, A. - SAlas, A., Evangelio y comunidad. Raíces bíblicas de la consagración a Dios en S. Agustín. M. 1978. 


\subsection{Los dos o tres motores básicos de la formación agustiniana:}

\subsubsection{Confianza en Dios: esperanza, optimismo...}

"El hombre era originalmente bueno", pero se ha deteriorado. Necesita volver al amor de Dios y escuchar la llamada a la conversión. "Entre todos los pensadores cristianos, ninguno ha respondido a esa llamada con tanta pasión y energía como san Agustín con su Noli foras ire, in te ipsum redi, in interiore homini habitat veritas"13. Nadie ha profundizado en el interior del hombre como san Agustín en las Confesiones, pero nadie ha hecho una crítica tan dura del hombre como el santo en La Ciudad de Dios. Pero, el Doctor de la gracia sabe que donde abundó el pecado esta sobreabundó.

El hombre tiene la luz divina de Dios: "Tú me conoces, y yo querría conocerme como soy conocido": De Trin X, 5. "Nada verdadero digo a los hombres que tú no hayas oído antes de mí, y tú no oyes de mí nada que tú no me hayas dicho antes": Conf $\mathrm{X}, 1$. Hay que conocer nuestra gran profundidad que es Dios "más íntimo a mí mismo que mi misma intimida". Él es nuestra fuerza y nuestro futuro. "Nadie puede decir: "No puedo" o "Ya es demasiado tarde": Conf. X, 3. La nueva medida, el impulso interior, es el don de Dios, el Espíritu Amor, concedido no por nuestros méritos, inexistentes por lo demás (Conf. IX, 13), sino por su infinita misericordia".

Y todo eso: "Es como ver el mundo y los acontecimientos de la vida con los ojos de Dios, con su optimismo, justificado por sus posibilidades, que Él transmite a los pobres, a los humildes, a los puros de corazón, a todos los que tienen hambre y sed de justicia: Conf 9,1 . Nunca más tristeza, resignación pesante a un destino inmutable, si no esperanza confiada en Quien hace nuevas todas las cosas ( $A p$ 21,5), en Quien ha cebado en el mundo el germen de la novedad que nosotros tal vez todavía aguardamos"14.

\subsection{2.- Confianza en el hombre: hacia un sano realismo}

El mundo moderno cree en la bondad de la naturaleza humana y su libertad, su deseo de perfección y ansia de responsabilidad. El cristianismo comparte este ideal porque el hombre es creación de Dios: "En su espíritu lleva grabada la imagen de la Trinidad. San Agustín ha estudiado

13 E. STEIN, La estructura de la persona humana. Madrid 1998, 19. En adelante ES.

${ }^{14}$ Mensaje de los Sups. Generales Agustinos para el XVI centenario de la Conversión y Bautismo de san Agustín, 10. 
con máximo rigor las diferentes posibilidades de concebir la imagen de Dios inscrita en el espíritu humano" (De Trin. IX, X) (...). "El hombre es sólo por Dios y es lo que es por Dios": ES 15. Conformar la propia libertad a la voluntad de Dios lleva a la perfección del hombre.

También hay que "dejar crecer" hacia la responsabilidad para "llegar a ser lo que se debe ser". Confiar en la gracia y convencernos de nuestra colaboración con Dios, y de la necesidad que tiene la persona en formación de "pasar de la educación a la auto-educación”. "¿Qué quiere decir que el hombre es responsable de sí mismo? Quiere decir que de él depende lo que él es, y que se le exige hacer de sí mismo algo concreto:puede y debe formarse a sí mismo": ES 141.

"Ser persona quiere decir ser libre y espiritual". Y esto significa dar forma a la propia vida, con una impronta apropiada. Para san Agustín nuestra forma es Cristo: De Gn. ad litt. 1, 9. Dios es la forma del hombre (Conf. 13, 32). Así hemos de formarnos y reformarnos. Contemplar la realidad con ojos agustinianos, convertirnos y actuar ${ }^{15}$. Ante los valores ideales se precisa una toma de posición de la voluntad, para configurar la propia vida de manera consciente y libre. Las cualidades personales facilitan el esfuerzo, con alegría, desde lo profundo del alma. Y ante la dificultad: "Unida a la voluntad divina, la fuerza para querer es infinita": ES 233.

Dios es nuestra fuerza en la debilidad: "Todo lo puedo en aquél que me conforta" (Flp 4,13; Conf. X, 31), porque su fuerza es nuestra nueva identidad; mas no la identidad de todo aquél que comienza a creer de forma exclusiva en su moralismo, estéril y descorazonador, sino antes que nada en la perenne juventud de Dios, pronto a sorprendernos cada día, porque diariamente nos renueva con sus recursos".

"A esta perspectiva sobre todo debemos convertirnos, a la perspectiva del don que serena, rejuvenece y produce esperanza".

"Es como pasar de la dependencia de la esclavitud (de la debilidad y del miedo) a la libertad. Ninguna meta queda excluida para nosotros y ningún fallo es irreparable" (...) "Es como revivir con nuevo espíritu, más amplio, universal. Mas no, el afanoso y corto producido por nuestro juicio, nuestras envidias, y recelos, sino el de Dios, que tiene paciencia y perdona, acoge y no indaga, hace fiesta y quiere que todos participen y nadie permanezca triste por no haber comprendido el amor" (Lc 15; Dives in Misericordia, 5,6$)^{16}$.

15 Agustinos en la Iglesia, 25.

${ }^{16}$ Mensaje de los Sups. Generales Agusts., 10 


\subsubsection{Confianza en las mediaciones, y en las tradiciones amorosas comunitarias, que conforman nuestra historia}

La actividad rectora del educador debe dejar cada vez más espacio a "la actividad propia del educando, para terminar permitiéndole pasar por completo a la auto-actividad y a la auto-educación" y respetar tanto los $l i$ mites del educando como las propias insuficiencias: ES 23; PI 29; RI 71. Por una parte la persona es un misterio, pero además "no debemos olvidar que con cada generación aparece algo nuevo, no enteramente comprensible para la generación anterior" (...) "Todo ello nos recuerda que el auténtico educador es Dios": ES 23. Sólo El sabe toda la verdad. "Los educadores humanos no son más que instrumentos en las manos de Dios": ES 23. Y deben actuar con un gran respeto a la vocación del llamado.

En la vida de algunas personas falta espontaneidad. "En estos casos, el educador debe comenzar volviendo a abrir lo que encuentra cerrado. No le será fácil": ES 25. La mirada del amor será un buen camino de entrada. La persona se cierra ante la indiferencia, la frialdad, las malas interpretaciones y la curiosidad irreverente. Hay que buscar la comprensión auténtica que no es nada fácil.

La comunidad religiosa, vivida desde la amistad, es, en todo este proceso, fundamental: PI 26-27. "El individuo humano aislado es una abstracción. Su existencia es existencia en un mundo, su vida es vida en común": ES 245. Y esta pertenece a la "estructura misma del hombre". Según Presbyterorum ordinis, 6: "Ninguna comunidad cristiana se edifica si no tiene su raíz y quicio en la celebración de la santísima Eucaristía, por la que debe, consiguientemente, comenzarse toda educación en el espíritu de comunidad". "Mientras que en casi todas las congregaciones la vida de comunidad juega un papel privilegiado en todas las etapas (PI 26), para nosotros, agustinos, se encuentra en el corazón de nuestra identidad y nuestro carisma" (RI 76)

Además, según E. Stein, desde el punto de vista pedagógico, "la acción eucarística es el acto pedagógico más esencial: la cooperación de Dios y el hombre, cuyo resultado es la adquisición de la vida eterna": EP 298. Por la Eucaristía, "cuando hace sacrificio de sí mismo junto con los dones, en sincera actitud sacrificial, el hombre es transformado en Cristo junto con esos mismos dones y se convierte de un modo plenamente real en un miembro vivo del cuerpo de Cristo. Y cuando en la sagrada comunión recibe en sí al Señor, lo introduce dentro de sí, y vive en Cristo y Cristo en él": ES 297-298. Así nos convertimos en Cristo y formamos su cuer- 
po vivo: VC 109: In Jn. Ev. 21, 8. Para nosotros los agustinos la Eucaristía es la fuente fundamental de la comunidad de vida en Cristo: Const. 88.

En la tarea decisiva de la formación, la comunidad viva, la vida religiosa de calidad, por encima del gran número, siempre seudo-consolador, resulta hoy imprescindible: "Sin duda alguna, estas comunidades fervientes son, más allá de los veinte siglos que las separan, la trasposición más fiel que actualmente existe de aquellas otras comunidades de los primerísimos tiempos del cristianismo en las que era fácil recordar al Maestro porque varios de sus miembros todavía habían vivido con El"17.

De ahí, que la comunidad sea esencial como "lugar teológico donde se realizan verdaderamente las personas", donde la fidelidad a nuestra historia y a nuestra espiritualidad nos pone en sintonía con los nuevos tiempos y la Iglesia del tercer milenio. "De esta fidelidad renace la esperanza de encontrar el entusiasmo (tamquam spiritualis pulchritudinis amatores) y aquella comunión (cor unum et anima una), que hacen Iglesia y pueden contagiar a los nuevos pobres, gozosos de formar parte de la familia de Dios"18.

Por lo demás, como es muy bien sabido: "No faltan signos positivos de comunidades acogedoras, capaces de contagiar con su estilo de vida, sobrio y gozoso, en el compartir y en el promover la fraternidad. Son sobre todo esas comunidades las que logran atraer un número mayor de jóvenes, tan sensibles a la coherencia de vida y a los ideales fuertes"19.

\subsection{Una palabra sobre Formación humana}

A nosotros, los agustinos, para bien y para mal, nada humano nos es ajeno, según el viejo proverbio recogido por Agustín. Esa es una tradición gloriosa para toda la Orden. La gente nos conoce por nuestra sencillez y por nuestra cercanía. Eso implica también un esfuerzo muy importante en mejorar la formación humana. Es relativamente fácil edificar un precioso edificio espiritual que responda, en la persona, a una satisfacción de carencias, demasiado humanas, pero poco religiosas. Entonces habremos edificado sobre arena.

La Iglesia nos presenta como primera exigencia de la formación, la de encontrar en la persona "una base humana y cristiana". "Muchos fra-

\footnotetext{
17 M. LEGAUT, Creer en la Iglesia del futuro. Santander 1988, 199.

18 Agustinos nuevos para el tercer milenio, Cap. Gen. 1995, 4.

19 Agustinos nuevos, 6.
} 
casos en la vida religiosa pueden atribuirse, en efecto, a fallos no percibidos o no superados en este campo. La existencia de esta base humana y cristiana no sólo debe ser verificada a la entrada en la vida religiosa, sino que hay que asegurar las evaluaciones a lo largo de todo el ciclo formativo, en función de la evolución de las personas y los acontecimientos": PI 33.

No despreciemos la sabiduría secular de la Iglesia. Hoy no hay que dar nada por su puesto y menos lo fundamental. Eso mismo nos dice el Plan de Formación Agustiniana: RI 74-75. Tenemos todos los medios necesarios para conseguir estos objetivos, y debemos utilizarlos adecuadamente, con verdadero amor a la Orden y a los hermanos ${ }^{20}$.

Por todo esto: Es preciso trabajar para conseguir una verdadera madurez humana que ha de conducir a:

$1^{\circ}$. Una identidad propia e integrada, en un proceso dinámico de crecimiento que comienza por la verdadera aceptación de sí mismo. Eso supone un abandono claro de la omnipotencia irresponsable, y de la búsqueda de seguridad paterna o materna.

$2^{\circ}$. Una aceptación de los demás, generosa y gratuita, desde la alteridad, el amor y la comunidad, frente al egoísmo del propio grupo de intereses.

$3^{\circ}$ Una verdadera aceptación del propio mundo, de nuestro tiempo y su historia, frente al cinismo y la desesperanza reinante, sin dejarnos seducir por el utilitarismo o el consumismo21.

Hoy no es fácil conseguir esta madurez porque la sociedad y, a veces nuestras comunidades, apoyan las inconsistencias individuales con verdadera complacencia 22 . Esto hace que las personas no lleguen a interiorizar, realmente, los ideales, ni a desarrollar los valores centrales de la vida religiosa que llevan a superar la dependencia afectiva, el vano exhibicionismo y el sentido de inferioridad.

Es necesario luchar para crear personas capaces de vivir, con gozo y en libertad, una vida comprometida y estable, frente al relativismo indeciso, personas maduras y creativas, con sentido del discernimiento personal

${ }^{20}$ La OALA ofrece un excelente material para trabajar la formación humana en Guía del acompañante, presentada por la Hna. L. Aliaga, SSJ. Un buen estudio pedagógico de la situación actual puede ver se en: La postmodernidad a debate, Análisis, Revista Colombiana de Humanidades 63 (1998) 83-111.

${ }^{21}$ A. Gomis, Madurez humana y crecimiento afectivo, Vida Religiosa 58 (1985) 197.

22 L. M. RULLA, Elementos de predicción y criterios de perseverancia vocacional, Confer 74 (1981) 315. 
y comunitario, y religiosos decididos, con entereza y equilibrio, bien fundamentados, frente a la inestabilidad actual 23 .

Todo esto debe hacerse mediante procesos que lleven a un encuentro auténtico de la persona con la comunidad religiosa y con nuestro mundo, clarificando las propias vivencias, descubriendo poco a poco y conociendo a fondo los propios sentimientos, en toda su realidad humana más autentica, con apertura a la propia cultura, con austeridad y disciplina de trabajo, y sentido de equipo, en un ambiente de confianza familiar y de profunda convivencia fraterna.

\section{Conclusión: - Para una renovación de la Formación hoy}

Para que la Formación actual pueda salir del bloqueo en que se encuentra, debe conseguir, de modo vital y radical, en cada individuo y en cada comunidad, las siguientes experiencias:

1.- Ser testimonio viviente y comprometido de la encarnación y la trascendencia frente al egoísmo y el secularismo.

2.- Ser testimonio viviente del amor a la oración y la contemplación frente al materialismo y la pragmatismo.

3.- Ser testimonio viviente de una comunidad vibrante de fe y amor verdadero frente al individualismo y la insolidaridad.

4.- Ser testimonio viviente de la necesidad del seguimiento de Jesús, en profundidad, con su estilo de vida sencillo, frente al consumismo y el culto a lo nuevo y efímero.

5.- Ser testimonio viviente del respeto a los ancianos y su sabiduría frente a la exaltación de la juventud y el culto a la productividad.

6.- Ser testimonio viviente de la virtud de la esperanza frente al pesimismo y la negación de la salvación a los marginados.

7.- Ser testimonio viviente de la misericordia de Dios y del amor de Cristo por los agobiados y oprimidos.

8. Ser testimonio viviente de la colaboración apostólica del hombre y la mujer en el mundo y en la Iglesia frente toda discriminación injusta.

9. Ser testimonio viviente del carisma de los fundadores hoy.

${ }^{23}$ Encuesta FoRe 97 del DIS, Confer 140 (1997), 685-687. 
10. Ser testimonio viviente del amor infinito de Dios al hombre, pues: "Tanto amó Dios al mundo que le dio a su Hijo único"24.

Algunas cuestiones de método. - La buena armonía y equilibrio de la comunidad de oración, la comunidad de convivencia y la comunidad pastoral facilitan mucho el proceso formativo ${ }^{25}$. Pero es importante definirse ante el pesimismo ambiental por una:

1.- Nueva ecología de la convivencia humana. Redescubriendo el mundo, el hombre y la realidad de la vida como don de Dios, desde el respeto y la alegría ${ }^{26}$.

2.- Una nueva imaginación social, solidaria, pacífica y tolerante, de paz y bien para todos (san Francisco), frente al individualismo y la violencia, con sentido inclusivo de la persona en la comunidad frente al exclusivismo y la marginación social.

3.- Una nueva forma de resolver los conflictos. No con un sentido de competición, o independentismo irredento, que nos llevará a una soledad estéril, sino con un deseo de comunión profunda y reconciliación auténtica que nos lleve a autotranscendernos, a superar nuestro egoísmo, y a entregarnos al bien común.

4.- Una nueva habilidad para vivir abiertos, para aceptar la novedad, la sorpresa, y los avances y retrocesos que nos presenta la vida. Siempre es tiempo de hacer la voluntad de Dios y nunca debe haber tiempo para oponernos a Dios. Debemos aceptar la vida, la comunidad y a Dios mismo, siempre sorprendente.

5.- Vivir con sentido de la compasión, a imitación de Cristo, con sentido fraternal, paternal y maternal. Este sentido de la misericordia divina nos hace sensibles a los seres humanos, especialmente a los marginados, para curar a los que sufren.

6.- Vivir alegres en la esperanza. Vivir, plenamente identificados con Cristo, la felicidad de la encarnación. Sentir el amor de Dios en la vida de cada día y, en medio de las adversidades y la cruz, avanzar por el camino Emaús: Lc 24, 13-35.

24 G. ARBUCKLE, Strategie di crescita nella vita religiosa. Paoline, Milano 1990, 54-55. Original en inglés.

25 G. ARBUCKLE, Strategie di crescita, 72-76.

26 D. Couturier, A Spirituality of Refounding, en G. A. Arbuckle \& D. L. Fleming (Eds.) Religious life. Rebirth through conversión. St. Paul. N.Y. 1990, 98-101. 


\section{Algunas aplicaciones a la formación para la vida religiosa}

\section{Las etapas de la formación: algunos puntos críticos}

0.1. Prenoviciado. El fin de Prenoviciado es facilitar una preparación adecuada para hacer el Noviciado. De ahí la necesidad de atención a la persona, para ver cómo viene al Noviciado, en su situación humana, religiosa, moral y cultural: PI 42, RI 86. El Prenoviciado debe conseguir:

1) Un mejor conocimiento de la persona y su propia identidad

2) Una profundidad más auténtica de la experiencia cristiana

3) Una aceptación positiva y gozosa de la propia vocación religiosa

4) Una experiencia adecuada de la comunidad agustiniana y sus tareas apostólicas.

0.2. Noviciado: Es un momento especial para cultivar la vida del Espíritu: RI 95. Además de afianzar el entusiasmo por los grandes ideales, hay que entrar en los problemas de cada persona, y prevenir 'el efecto túnel'. Los especialistas explican así el 'síndrome del túnel': En una congregación religiosa se tenía la impresión de que el programa de formación del noviciado era excelente y los novicios profesaban con signos evidentes de crecimiento auténtico. Pero su programa no parecía funcionar cuando llegaban los estudios universitarios y la experiencia pastoral.

Los expertos han descubierto que lo que sucede es más bien que los candidatos pasan los primeros años de la vida religiosa y de formación como quien atraviesa un túnel de lavabo, donde quedan limpios por fuera, pero sin cambio interior auténtico. Los problemas en vez de afrontarse se callan o se enmascaran. Lo mismo pasa con la interiorización de los valores en gratuidad y generosidad ${ }^{27}$. La experiencia de la vida pondrá luego al descubierto abundantes inconsistencias.

0.3. Profesorio. El tiempo de votos temporales, es la comunidad en acción, celebración, convivencia, oración, estudio y apostolado. Es preciso caminar hacia una formación integral e integradora que descubra el profetismo de la consagración y los votos.

Una dificultad muy importante, en la formación actual, proviene de pensar y hacer creer que con la primera profesión ya se ha conseguido todo y se ha terminado todo. La Iglesia establece una norma que parece ser sistemáticamente olvidada o despreciada por todas las Congregacio-

27 L. M. Rulla, F.Imoda, J. Ridick, Struttura psicologica e vocazione. Torino 1977, 188-9. 
nes: "La celebración litúrgica distinguirá con cuidado la profesión perpetua de la profesión temporal que debe celebrarse 'sin ninguna solemnidad particular'. Esa actitud es lo que llama un autor actual: La existencia como plenitud de la excelencia ${ }^{28}$. Así se da la impresión que uno ya es tan bueno que no puede mejorar. Por tanto la Formación es un puro trámite inútil.

Si alguien dice lo contrario, será un impertinente que se dedica a buscar falsos problemas. En ese caso, el joven religioso se declara víctima de la institución formativa o de tal o cual formador, se convierte así en un mártir autoproclamado a quién, sin responsabilidad alguna por su parte, todos deben cosas, por lo que se niega a crecer y poner el esfuerzo que debe conducir su desarrollo más allá de su mundo infantil 29.

Esta situación neutralizadora de la formación hace que se facilite mucho el 'todo vale' y la indecisión ante nuevos compromisos como la Profesión solemne o la Ordenación sacerdotal. Y, entonces, se plantea el problema de saber si estamos ante personas simplemente inseguras o más bien hipotecadas. Según Marcia, la identidad de la adolescencia, aunque no limitada a ella, tiene cuatro características:

“a) moratoria, estado propio de personas atrapadas en plena crisis de identidad, debatiéndose con cuestiones ocupacionales y/o ideológicas, con un vago compromiso personal;

b) difusión de la personalidad, típica de aquellos adolescentes y jóvenes que, habiendo pasado por una experiencia o período de toma de decisiones, siguen irresolutos sin situarse en una dirección vocacional e ideológica;

c) hipoteca (forclosure), estatus de identidad de aquellos individuos ya comprometidos en posiciones ideológicas y profesionales, pero impuestas o elegidas por los padres, más bien que adoptadas por propia decisión;

d) el logro o realización de identidad, estatus de las personas que, habiendo vivido un período de crisis y de opción, se hallan ya enderezadas a metas vocacionales e ideológicas bien definidas" 30 .

No es una vana cuestión que, al hablar de la pedagogía de la obediencia, la Iglesia advierta que: "para darse en obediencia, es preciso ante todo existir. Los candidatos necesitan salir del anonimato del mundo de la técnica y reconocerse y ser reconocidos como personas, ser estimados y amados": PI 15.

28 A. FinkielKRAUT, La derrota del pensamiento. B. $1987,2^{\text {a }}$.

${ }^{29}$ P. BRUCKNER, La tentación de la inocencia. B. 1996, $2^{\mathrm{a}}$.

30 M. Carretero, Teorías de la adolescencia, en A. Marchesi, y otros, Psicología evolutiva. $3^{\circ}$. Adolescencia, madurez, senectud. AU, M. 1986, $2^{\mathrm{a}}$, 113. 
Otra dificultad que afecta al proceso formativo es el mesianismo juvenil y su práctica pastoral. Algunas personas, cuando vienen a la vida religiosa o desean ser sacerdotes no parecen buscar tanto seguir a Cristo como prepararse a ser Mesías. Este tipo de individuo busca "un camino personalísimo e inédito inspirado en aquellos pasajes de la vida de Jesús que pueden ser leímos (mal leídos) en clave de protesta antiinstitucional; evangelio se hace coincidir con anticonvencionalismo, verdad con sinceridad, etc. No viene a prepararse para presbítero sino para mesías" (...) "está incapacitado para representar a otro (¡no le hagáis embajador (ni de Cristo) que fastidia la embajada!)"31.

Estos personajes, con una conciencia demasiado clara de ser distintos, únicos, mesiánicos, creadores, heroicos, marchan en carro triunfal, con tambores de auto-bombo incorporados, con mucha indefinición y poca determinación. Su infierno es el anonimato, la normalidad, y el color gris ordinario de la vida de cada día, que les hace suspirar por una vida religiosa llamativa que no acepta lo humildad de Cristo que se anonadó a sí mismo y se hizo pobre por nosotros "actuando com un hombre cualquiera" y "pasando por uno de tantos"(Filp 2,7-8).

\section{Formación en la vida de Oración (Fowler)}

1.1. Estadio de fe infantil y oración. El niño recibe la fe de sus padres y parientes como una parte más de su herencia. El niño, ya mayorcito se convierte en satélite de los padres para conseguir lo que quiere, y cuando no lo consigue pierde la fe. En ocasiones, la idea de un Dios todopoderoso y el deseo de omnipotencia se unen para crear una especie de ilusión de perfección infinita. La persona desarrolla una omnipotencia infantil, completamente fuera de la vida real, sin sentido de la generosidad ni de la gratuidad (VC 104). Surge aquí como un deseo inútil de una falsa omnipotencia ${ }^{32}$.

Por desgracia, algunos todavía viven una religión del miedo y creen en el Dios de la expiación insaciable y la violencia religiosa (R. Girard). Ven a Dios como un ser justiciero, sin piedad ni misericordia, inagotable en sus exigencias. Quizá es un yo ideal que no quiere bajar del trono y se

31 L. TrujILlo, Aproximación valorativa a la espiritualidad de los sacerdotes diocesanos, en La formación espiritual de los sacerdotes según Pastores dabo vobis. M. 1995, 33-34.

32 A. CENCINI, Vivere riconciliati. Aspetti psicologici. Bologna 1989, 4a, 12. 
está autodestruyendo. Esto es también un dolor enorme e inútil para la persona, y debemos ayudar con paciencia y sabiduría.

Otros, en el extremo contrario, viven a Dios como a una abuela: Todo lo que hacen lo hacen siempre bien. La abuela me da caramelos, me quiere mucho y para ella nunca hago nada malo. Por tanto, el que me corrige es porque me quiere mal.

1.2. Estadio de la fe mítica literal. Es una fe adolescente, aprendida de memoria. Se trata de un conjunto de 'historias' que hablan de una gran aventura. El sentido literal se toma como algo dogmático que ante los cambios culturales, va a crear graves problemas. La fe se acepta por la autoridad de las personas que han contado la historia sagrada. No hay experiencia personal de la fe $\mathrm{f}^{33}$.

1.3. Fe joven en grupo y oración. Esta fe proviene del hecho de pertenecer a un medio cultural o a un grupo concreto. La oración es una experiencia de amistad que nos sumerge en el grupo. Aquí la oración tiende a la auto-adoración. Durkheim decía que la religión es un acto por el que el grupo se da culto a sí mismo. La fe, en la primera juventud, depende mucho de un grupo concreto y de un ambiente cultural determinado: Uno cree porque el grupo cree, las razones para creer nunca son analizadas ${ }^{34}$.

Paul Vitz ha escrito sobre la religión como psicología del culto a sí mismo ${ }^{35}$. La religión como autocomplacencia y auto-realización permisiva lleva a la desintegración de la persona, la familia, y la comunidad. Así el hombre se hace un diosecillo. $\mathrm{O}$. González de Cardedal ha criticado un cristianismo que cree más en sí mismo que en Dios, confía más en sí mismo que en Dios, se ama más a sí mismo que a Dios, y se adora a sí mismo, en lugar de Dios, lo que es una idolatría. El individualista, vive en su globo celestial y busca un Dios como 'exaltación de su yo'36.

Así se crea un idealismo entusiasta que se volatiliza cuando falla la recompensa. Es la personalidad hipotecada. Hay un culto al grupo, del que todo se espera, porque implica compañerismo, hacer cosas, divertirse juntos, atención personal y preocupación por los demás. Al desintegrarse el grupo se pierde la fe.

${ }^{33}$ G. ARBUCKLE, Out of caos. Refounding Religious Congregations. Paulist Press. N.Y. 1988.

34 J. W. FOWLER, Stages of faith: the Psychology of Human Development and the Quest for Meaning. Citado por G. Arbuckle, Understanding Refounding and the Role of Conversión, en G. Arbuckle \& L. Fleming (Eds.) Religious Life, 67-68.

35 P. VITZ, Psicologia e culto di sé. Bologna 1987, 70, 101.

36 R. N. BELLAH, S.M. Tipton, Hábitos del corazón. AU, M. 1985, 301. 
1.4. Fe adulta individual y oración. Aquí la fe o se personaliza o se evapora. El joven religioso se da cuenta que tenemos un amigo que nos ama, y su nombre es Jesús. Entonces, se cumple la experiencia de que orar es 'tratar de amistad' como dice santa Teresa. Y el cristianismo se vive como la historia de una amistad 37 . Pero hasta llegar a este momento, en el proceso de personalización, se comienza por rechazar esquemas impuestos y tradiciones recibidas sin asimilación personal. Se tiende a polarizar la fe, de modo radical y exclusivo, entre amor de Dios o amor al prójimo, fe o libertad, razón o revolución, oración o acción social, conformismo o rebeldía.

1.5. Fe madura integrada y oración. Amor incondicional y entrega serena y profunda. Es una fe equilibrada en su plenitud. La persona sabe integrar todos los valores la vida cristiana: amor propio y amor al prójimo, amor a Dios y amor fraterno, oración y compromiso social. Aquí la fe se vive con una profundidad más plena, llena de la paz el alma, y desarrolla una relación de intimidad con Dios. Pero aún quedan muchos miedos, y falta generosidad, gratuidad y entusiasmo.

1.5.1. Fe plena que es confianza en Dios y en el mundo. Aquí la persona reconcilia totalmente oración y acción, yo y los otros, fe y razón, Dios y mundo. Hace concretos los imperativos del amor y la justicia, y remueve nuestros pobres criterios de 'normalidad'. Nace así una personalidad fuerte, con profunda paz interior, basada en la compasión y la acción por la justicia que surge de la unión amorosa con Dios. Ejemplos para nosotros pueden ser san Francisco de Asís, o santo Tomás de Villanueva. En nuestros días, podemos señalar a Ch. de Foucauld, Merton o la Madre Teresa, profundamente orientados a Dios desde la libertad individual y el compromiso social. No es fácil alcanzar esta meta.

\section{Formación para la vida de Comunidad}

\subsection{Las edades de la comunidad y la comunidad por edades}

La comunidad religiosa, como la comunidad cristiana, no siempre se ha vivido del mismo modo, ni con los mismos acentos.

Así, vemos que en la Edad Antigua, en los primeros tiempos del cristianismo, hay una comunidad ideal carismática, en la que todos viven para todos, con gran libertad y entusiasmo, y ponen todo en común (Hch 2, 44-

\footnotetext{
${ }^{37}$ S. GaliLEA, La amistad de Dios. El cristianismo como amistad. M. 1987.
} 
47). Es la edad de oro de la comunidad. A veces se ve esa primera comunidad cristiana como carente de problemas. Esta visión de la comunidad no presenta objetivamente la realidad. Y crea un ideal excesivamente idealista.

En cambio, en la Edad Media, la comunidad es mucho más sistemática que carismática. Parece que todos hacen lo mismo y de la misma manera. Los horarios, las actividades y las celebraciones comunes unifican todo el grupo. El ideal está muy alto y nadie puede discutirlo. Aquí la rutina es el mayor peligro para la comunidad que puede convertirse en una realidad mecánica, sin espíritu y sin alma. La estructura se impone a todo y las personas no crecen. Esto es lo que sentían bastantes religiosos antes del Concilio Vaticano II.

La comunidad, en la Edad Moderna, será una comunidad de acción, pues la modernidad es actividad. En esta comunidad lo importante es el trabajo, la misión, el apostolado. No interesa tanto la persona o la comunidad como su acción eficaz. Es un tipo de comunidad que va a quemar mucho a la persona, pues le falta interioridad y amor. Ha sido un tipo de comunidad frecuente en el postconcilio.

La comunidad, en la Edad Contemporánea, intenta integrar todas las dimensiones fundamentales de la vida religiosa. Se busca sentido humano auténtico, cultivo de la oración y la vida interior, amor a la convivencia y a la vida de amistad, y también un sentido profundo de la misión ${ }^{38}$. Así queremos hoy la nueva comunidad, integrada e integradora, desde el personalismo agustiniano y la libertad liberadora.

Por otra parte, en todo proceso formativo, la edad de la persona también cuenta mucho. Para el religioso joven la comunidad es como un mito que lo invade todo, la persona de edad madura tiende más al individualismo y a centrarse en su trabajo. La persona mayor puede tener la tentación de aislarse y mirar sólo al pasado. Todos necesitamos generosidad y gratuidad para valorar las distintas dimensiones de la vida religiosa y no quedarnos sólo con un aspecto de la misma, por importante que sea. La vida de comunidad no es sólo vida de oración, ni sólo convivencia, ni mero apostolado.

\subsection{La vida de comunidad y sus diversos acentos}

La vida de comunidad no siempre se ha vivido igual, ni ha tenido la misma función, en la vida religiosa, a lo largo de su historia. En algunos

${ }^{38}$ La Vida Fraterna, 66-86. 
momentos se ha insistido sobre todo en la dimensión ascética de la comunidad: la comunidad requiere un espíritu de sacrificio que nos purifica e integra, velis nolis, en la vida religiosa. La comunidad es la máxima felicidad y también la máxima penitencia ${ }^{39}$.

Otra forma de vivir la comunidad es la comunidad apostólica, o comunidad para la misión. En ella lo único importante es la misión. La comunidad no surge, ciertamente, para encerrarse en sí misma, pero tampoco es un simple medio de la misión porque entonces, las personas serán instrumentalizadas. Puede que incluso vivan solas, aisladas, aunque con una misma idea y un mismo compromiso con la misión. Es la clásica comunidad apostólica, jesuítica, de otro tiempo.

La comunidad de convivencia es hoy la más celebrada. En ella se valoran mucho la calidad de las relaciones humanas según la vida evangélica. Aquí la comunidad es el primer apostolado pues es la vida apostólica ${ }^{40}$. El diálogo, la comunicación de la fe y la experiencia de la vida son de capital importancia 41 .

Por otra parte, hay comunidades con una estructura muy fuerte y poco espíritu, y hay comunidades con mucho espíritu y una estructura muy débil. Cada una de las opciones tiene sus propios problemas. Del mismo modo, en unos lugares se promueve sobre todo la creatividad, el individuo, la iniciativa, el sentido de futuro, mientras que en otros se valora más bien el comunitarismo, la identidad, el pasado y la subsistencia ${ }^{42}$. A unos les invade el comunitarismo y a otros el individualismo, pero hay que buscar un camino intermedio donde la persona y la comunidad puedan encontrarse en paz por un impulso de crecimiento mutuo que ayude a estas dos dimensiones del ser humano ${ }^{43}$.

\subsubsection{El análisis del crecimiento moral en Kohlberg y su aplicación a la vida de comunidad}

Para llegar a una verdadera vida de comunidad es necesario pasar del entusiasmo comunitario a la vida comunitaria, de la comunidad ideal a la entrega a la comunidad, de la vida en comunidad al servicio de la comunidad, del mártir autoproclamado al realismo de la convivencia, y del

\footnotetext{
39 La Vida Fraterna, 28, 38.

40 Agustinos en la Iglesia, 10.

41 G. ARBUCKLE, Understandig Refounding, 74.

42 G. ArbuCKLE, Strategie di crescita, 208.

43 La Vida Fraterna, 25.
} 
santo individualista al hombre comunitario, mediante la conversión al Dios de la comunión.

Para eso, es preciso que la persona vaya creciendo en su dimensión moral y religiosa. Kohlberg y Loevinger han descrito diversas etapas de desarrollo, personal y moral, que podemos traducir, con ciertas adaptaciones, a nuestra vida:

1. En la comunidad más elemental, la persona actúa por temor y miedo o por búsqueda de placer. Así crea una comunidad en la que busca gratificación, por una parte, y huida de lo que no es agradable, por otra. Se trata de una vivencia comunitaria elemental que funciona por temor al castigo o por conseguir recompensas.

2. En la comunidad de cumplimiento, se mantiene la ley y el orden, porque así está establecido, pero sin ir más allá ni poner alma en la vida. Se respeta el pacto social, porque así está mandado, pero falta vivencia interior y amor comunitario. Se hace lo que hay que hacer porque todo está bien ordenado. Pero este orden no tiene vida.

3. La comunidad de la imagen. La persona actúa como se espera de ella, tiende a mantener su imagen y hacer lo que se le pide. La custodia de la imagen hace los comportamientos. Se hace lo que todos hacen, siempre que haya recompensa, pero se rompe el contrato cuando ya no beneficia o el grupo no me refleja como quiero que se me vea y entienda. La falta de respuesta del grupo conduce a la rebeldía y al hundimiento vital y religioso. La persona carece aún de verdadera interioridad y de convicciones propias.

4. La comunidad interiorizada, es un paso más adelante que ya no es tan convencional. Hay un respeto a las normas que no es temor ni cumplimiento sino sentido comunitario de un patrimonio común de tradiciones amorosas. Es una experiencia de grupo que vive valores comunes y una mística comunitaria. La responsabilidad se va imponiendo, por las propias convicciones, pero la gratuidad y la generosidad tienen aún poca fuerza.

5. La comunidad integral e integradora, es la comunidad que buscamos y que tenemos por ideal a realizar. En ella la persona crece con su 
ideal de generosidad y gratuidad, de desprendimiento y compromiso, de sencillez y profundidad. La mística es ahora la vida, la fe viva que se encarna en la vida concreta de oración, de comunidad y apostolado. La libertad personal y la acción comunitaria se completan mutuamente. Autonomía e institución se enriquecen plenamente.

\subsubsection{Algunas cuestiones de método en la formación comunitaria}

Hoy todos estamos de acuerdo sobre ciertos modelos de comunidad que no debemos proponer ${ }^{44}$. Este es el caso de los modelos autoritarios que conducen a una falsa interiorización e integración de la vida religiosa, a una sumisión excesiva y a una obediencia ficticia. Lo mismo hemos de decir de los modelos libertarios o asamblearios $^{45}$ que no forman a la persona ni le ayudan a integrar su vida con libertad, sencillez, amor y laboriosidad, y una sana disciplina.

También debemos tener cuidado con las comunidades muy adaptadas a la situación social, de las felices clases medias, que toman por el mismo Evangelio lo que todo el mundo hace, aunque sea muy poco evangélico. En cuanto a las comunidades insertas, en medios difíciles de marginación e injusticia, que tienen una gran riqueza vocacional (VC 82), debemos cuidarlas mucho, para que no dañen el proceso formativo, como nos advierte la Iglesia (PI 28), especialmente cuando se convierten en comunidades demasiado coflictivas e incluso antiinstitucionales.

Pero, sobre todo, queremos llamar la atención sobre las comunidades 'como sí' y la comunidad 'incubadora', porque pueden parecernos válidas, pues viven de un modo 'políticamente correcto', pero explican bastante bien algunos procesos extraños, a los que se ha referido C. Boff, y que vemos en abandonos muy tempranos y repentinos.

- Las comunidades como sí, son comunidades flexibles y actuales, bien adaptadas al medio social, y con espacios internos cálidos y armoniosos que si fallan crean protestas. La autoridad es bien aceptada mientras defiende los propios intereses. Sus proyectos comunitarios son utópicos e inconcretos, y suelen cumplirse poco. Pero para actuar así, siempre hay muy buenas disculpas.

Las personas no han entrado, a fondo, en su propia vida ni han hecho una verdadera experiencia de Dios. No hay personalización de la formación ni auténtica responsabilidad. Se pide más libertad pero se responde poco. No hay confianza verdadera. Las compensaciones afectivas son aquí

44 Encuesta FoRe 1997, 700-706.

45 La Vida Fraterna, 24. 
algo frecuente: reproches a los demás, individualismo, murmuración, secretismo, relaciones difusas y confusas, confusión de papeles pastorales, amiguismo, búsqueda de padre, madre y abuela...

Es necesario analizar abiertamente la situación y entrar en los problemas, animar a asumir la propia vida y las propias responsabilidades y caminar hacia un "Dios Padre/Madre que nos conoce y acoge para sanarnos de todas nuestras heridas y mostrarnos el camino de la verdadera trascendencia y fecundidad" 46 .

- Las comunidades incubadoras son comunidades con una actitud individualista ante la vida y una imagen de Dios difusa. La comunidad se busca como grupo de amigos para vivir su satisfacción, armonía y bienestar. Se hace un reduccionismo absoluto de los demás valores. El centro no es Dios y su Reino, sino el bienestar y la realización personal.

La verdad es que son comunidades que "a primera vista" quedan bien. Valoran la formación, son amantes de todo lo comunitario, incluso tienen oraciones cálidas y afectivas, y son muy de estar todos juntos. Valoran la acogida como lo más importante, pero tienen una idea bastante subjetiva de la vida religiosa.

Encajan mal el conflicto y las estructuras establecidas. No soportan la cruz ni la contrariedad. Buscan excesiva satisfacción en las relaciones y sienten miedo ante las diferencias. El sentido de dependencia y reactividad infantil está todavía muy presente. No saben lo que es trascenderse y cultivan el egocentrismo ${ }^{47}$.

En estas comunidades se mantiene "la fantasía del amor incondicional y el idealismo etéreo, por lo que las relaciones de dependencia, celos, la envidia, el control a base de silencio, la persecución de unos a otros y la queja por lo no recibido exigen muchas horas de reuniones. Conflicto es todo aquello que no ayuda a conseguir lo que deseo" (...) "Ni el realismo de la vida, ni la fuerza de voluntad, ni la aceptación de la soledad, indispensable, son experiencias familiares y practicadas".

"La misión interesa en cuanto gratifica y se abandona en cuanto resulta amenazante. Se consume vida religiosa y trato con Dios, pero no se hace experiencia vital. En estas comunidades se pretenden saldar muchas hipotecas de amores e ideales abortados en la infancia y juventud. Lo peor es cuando pasan los años y todavía estamos ahî".

"La solución pasa por una maduración lenta y realista. Por la necesidad de diferenciarse y afirmarse en la propia identidad personal y sexual;

46 L. Arrieta, Convivir con la afectividad. VI. 1992, 2a 46.

${ }^{47}$ L. M. RulLA, F. Imoda, J. Riddick, Struttura psicol. 186. 
por entender que la experiencia vocacional no se inscribe en parámetros de bienestar personal, en los que Dios por su bondad no se mete para nada, sino en el don de Dios que nos capacita con vocación de amor y nos invita a compartir su proyecto de Reino" 48 .

\section{Formación para la Misión}

Para que la experiencia pastoral lleve al crecimiento del apóstol es preciso pasar: del entusiasmo teórico al trabajo pastoral, de la pastoral que arregla todo a una pastoral responsable, del servicio a los laicos a la comunión con los hermanos creyentes, del pastor único omnipresente a la comunidad de comunidades. Del complejo de Mesías a seguidor de Jesús, el Buen Pastor del pueblo de Dios. Se trata de reforzar la identidad del apóstol para que pueda convertirse en presencia de Cristo entre los hombres y mujeres de nuestro tiempo.

A este fin, hemos de promover comunidades bien definidas, en su espiritualidad carismática y su coherencia interna, de modo que no se dañe "la identidad y la unidad del mismo Instituto y la unidad de vida de cada uno de sus miembros" 49 . Pero, además de evitar la confusión 'hacia fuera', es necesario promover la identidad personal del religioso, de modo que sepa actuar, siempre, como tal y desde la comunidad, a la que se confía la misión, y quede reforzado su sentido de identidad y pertenencia.

\subsection{La identidad humana hoy}

El hombre es un buscador de amor, por la insatisfacción de su corazón, y de verdad ante la inseguridad de la vida. Con frecuencia, suele encontrar un padre o/y una madre buena que iluminan su camino. Pero, a veces no hay tanta suerte, y los problemas se enmascaran, en el dogmatismo o en el relativismo, para huir de la realidad. Así, la persona falsifica su vida y confunde su camino.

En ocasiones, en esa búsqueda de seguridad, a toda prueba, se trata de conseguir un padre protector, al que se somete incondicionalmente, o una madre super-protectora que anula su personalidad a cambio de afec-

48 L. ARRIETA, Convivir 50.

${ }^{49}$ La Vida Fraterna 62 c. 
to y amor. Entonces la identidad humana y pastoral se encuentra en grave peligro 50 .

\subsection{La identidad cristiana de los religiosos jóvenes}

El religioso joven necesita encarnarse sin miedo. Tiene que nacer de nuevo, para hacerse un ser autónomo y libre, que pueda sentirse amado incondicional y gratuitamente, pues "Cristo da a la persona dos certezas fundamentales: la de ser amado infinitamente y la de poder amar sin límites" 51 . Anunciar esta buena noticia, convencidos de que es una buena noticia, y anunciarla con preparación y competencia es algo fundamental. Esta actitud juvenil, integrada en su tiempo y en su edad, es hoy mucho más necesaria para que pueda crecer un nuevo estilo pastoral que consiste en animar, dar vida, dar aliento, ser profeta de nueva vida (VC 84-95) y reconocerse cristiano como alma del mundo (Carta a Diogneto).

\subsection{Problemas de identidad en los religiosos jóvenes}

El religioso joven está enamorado de su juventud. Pertenece a un grupo muy valorado y envidiado por toda la sociedad. Le cuesta abandonar la cresta de la ola juvenil. Además pertenece a una generación que es la suya y acepta incondicionalmente. Cuando hay conflicto entre juventud e identidad religiosa la situación se complica.

A veces, el joven religioso, se centra mucho en los ideales de su juventud y no es capaz de trasmitir, con claridad, la experiencia cristiana y religiosa de su vida. $Y$ puede quedarse más en un animador de tiempo libre que en un agente de pastoral misionera. Este joven religioso libra una dura batalla, entre el sentido 'común' y el sentido evangélico, en la que: "Decantarse y definirse sin desarraigarse le resulta especialmente costoso. Algunas secularizaciones demasiado tempranas y demasiado fáciles pueden tal vez explicarse desde esta 'doble pertenencia'"'52.

50 J. L. DEL MORAL, Director de Misión Joven, La Pastoral en la Formación Inicial. Valladolid 1. 5. 1999. B. Goya, Formación integral a la vida consagrada. M. 1998, 165-191.

51 La Vida Fraterna, 22.

52 J. Ma . URIARTE, Presbíteros Jóvenes: Asumir espiritualmente su nueva identidad, en La form. espir. de los sac. según PDV, 83. 


\subsection{Para realizar una pastoral con garantías}

Es preciso recuperarse de la 'pérdida del sentido del misterio' y de 'la debilidad de la cultura de referencia' con una experiencia gozosa de Cristo (EN) que evite la indefinición, el narcisismo, el pragmatismo paralizante, la falta de entusiasmo y convicciones, y renueve el amor a la 'belleza espiritual' (¡tarde te amé, belleza infinita!) que iluminó a los santos de todos los tiempos, más allá de los pequeños intereses vitales.

Para eso, es necesario el diálogo, la oración como experiencia de amistad con Dios, la vida consagrada como opción radical y profética con memoria social, sentido de libertad y de los grandes ideales encarnados en la vida concreta, la comunión y el acompañamiento personal que 'permita al máximo la apertura y la confianza' (Cencini) y que anime a soñar de nuevo un futuro ilusionante.

\subsection{Algunas cuestiones de método}

Es necesario que la pastoral sea verdaderamente comprometida para los candidatos y no un mero divertimento ${ }^{53}$. Por tanto, debe estar realmente planificada "con el apoyo de los formadores y otros especialistas en el tema" (RI 104- 105), y debe hacerse de un modo "gradual": RI 104. Además, no debe perturbar los estudios, que son fundamentales en la formación actual para la interiorización carismática de la vida religiosa, aunque estos deban orientarse siempre con sentido pastoral: RI 103.

Dado que el acompañamiento personal es "el principal instrumento de formación" (VC 66) la revisión, en diálogo personal, del proyecto pastoral, debe hacerse regularmente. Y dado que todo apostolado está encomendado a la comunidad, la revisión comunitaria del proyecto pastoral debe ser algo frecuente: RI 106, 110.

Para facilitar a los profesos de votos temporales una preparación adecuada en los diversos campos de la pastoral conviene organizar encuentros periódicos con religiosos que ya trabajan en esos campos de apostolado, señalados en nuestras Constituciones: Const. 157-199. En este mismo sentido conviene facilitar experiencias apostólicas, en los distintos campos de apostolado, ya en la propia cultura ya en otras diversas: RI 110112.

Finalmente es preciso recuperar el sentido agustiniano del estudio como alimento de nuestra vida religiosa, comunitaria y apostólica. Como

53 G. ARBUCKLE, Strategie di crescita, 222-229. 
nos ha recordado recientemente el Papa: "Pero, más allá del servicio prestado a los otros, la vida consagrada necesita también en su interior un renovado amor por el empeño cultural, una dedicación al estudio como medio para la formación integral y como camino ascético, extraordinariamente actual, ante la diversidad de las culturas. Una disminución de la preocupación por el estudio puede tener graves consecuencias también en el apostolado, generando un sentido de marginación y de inferioridad, o favoreciendo la superficialidad y ligereza en las iniciativas": VC 98.

Este escrito que ahora publicamos, fue, inicialmente, una Conferencia pronunciada, en el Congreso Internacional de Formadores Agustinos celebrado en Roma y S. Gemigniano, el 5.7.1999, y ha sido revisado para actualizarlo. Ahora, cobra una importancia especial la aportación del personalismo antropológico agustiniano de la gran pensadora Edith Stein, canonizada por el Papa Juan Pablo $\mathrm{II}^{\circ}$, con su nombre de vida religiosa: sor Teresa Benedicta de la Cruz.

En efecto, como ya quedó dicho más arriba, para Edith Stein, el hombre "puede y debe formarse a sí mismo" (ES 141), ya que, en la voluntad humana, "unida a la voluntad divina, la fuerza para querer es infinita": ES 233. De ahí, la importancia de favorecer "la actividad propia del educando, para terminar permitiéndole pasar por completo a la auto-actividad y a la auto-educación": ES 23. "Todo ello nos recuerda que el auténtico educador es Dios": ES 23. Los hombres somos sólo sus mensajeros, que no es poca cosa ni nada desdeñable. Y, que la confianza en Dios y la confianza en el hombre y en las tradiciones amorosas comunitarias que configuran nuestra historia son decisivas en toda formación humana y religiosa, como decía Edith Stein.

\author{
Domingo Natal Álvarez \\ Estudio Teológico Agustiniano \\ Valladolid
}

